\title{
Meetings and Notices
}

PLEASE NOTE: Information regarding Meetings, Conferences, etc. for publication in the Journal should be notified to the Editorial Secretary at Wessex Nuffield Hospital at least three months prior to the event.

\section{POSTPONEMENT OF MEETING}

The following notice has been received from:

Regional Conference on Spinal Cord Injury: Israel Association of Physical Medicine and Rehabilitation 25-28 November 2001, Herods Sheraton Resort, Eilat, Israel.

Dear Participant

The recent events in Israel have led to serious discussions with the local organizing committee as to whether the Israel meeting should be held as scheduled. Although the location of the meeting is well within Israel proper and is safe by any standard, some members have expressed concern. Therefore we have decided to postpone the conference until further notice.

Further information from: Conference Chairman, Prof. Avi Ohry, 1 Nirim St., Tel-Aviv, PO Box 9352, Tel-Aviv 61092, Israel. Tel: 972-3-6384444; Fax: 972-3-6384455; e-mail: info@ortra.co.il; Website: www.ortra.com

I would urge you to spread the word to all interested parties, although most will have received this same letter.

Sincerely

Sagit Ishay

Conference Coordinator

\section{International Congress of Polish Rehabilitation Society}

29 August-1 September 2001, Konstancin/Bydgoszcz. Further information from: Katedra i Klinika Rehabilitacji AMB, ul. Maria Curie-Sklodowska 9, 85-094 Bydgoszcz, Poland. Tel: +4852 3400-814; +4852 3400-788 ext. 330; e-mail: Klreh@amb.bydgoszcz.pl; http://www.ptreh-congress. amb.bydgoszcz

47th Annual Scientific Conference of the American Paraplegia Society

4-6 September 2001, Riviera Hotal, Las Vegas, Nevada, USA. For further information please contact: APS, 7520 Astoria Boulevard, Jackson Heights, NY 113701177, USA. Tel: (718) 803-3782; Fax: (718) 803-0414. Deadline for submission is January 14, 2001.

XIth International Symposium on Cholinergic

Mechanisms - Function and Dysfunction \& 2nd Misrahi Symposium on Neurobiology

21-28 October 2001, Eilat, Israel. For further information please contact: Secretariat, XIth International Symposium on Cholinergic Mechanisms - Function and Dysfunction \& 2nd Misrahi Symposium on Neurobiology, c/o Kenes International, PO Box 50006, Tel Aviv 61500, Israel. Tel: 9723 5140018/9; Fax: 9723 5140077 or 9723 5172484; e-mail: cholinergic@kenes.com; Website: www.kenes.com/cholinergic

\section{International Conference on Spinal Cord Lesion Management}

6-8 November 2001, Dhaka, Bangladesh. Further information from: Centre for the Rehabilitation of the Paralysed (CRP), P.O. CRP-Chapain, Savar, Dhaka1343. Tel: 8802 7710464, 7710465, 8802 7711766; Fax: 8802 7710069; E-mail: crp@bangla.net

\section{The Fourth Scientific Meeting of PROPARA}

8-9 November 2001, Palais des Congrès, Montpellier, France. Further information from: Prof. Ch. Herisson, Dr. F. Ohanna, 263 rue du caducée 34195 Montpellier Cedex 5/France. Tel: 330467046850; Fax: 3304670468 76; E-mail: medical@propara.com

The 36th Scientific Meeting of the Japan Medical Society of Paraplegia

8-9 November 2001, Across FUKUOKA, Fukuoka, Japan. Further information from: Chairman, Prof. Eiji Iwatsubo, LWC Spinal Injuries Center, 550-4, Igisu, Iizuka, Fukuoka 820-8508 Japan. Tel: (81) 94824 7500; Fax: (81) 94829 1065;

E-mail: eiji1820@orange.ocn.ne.jp

\section{European Academy of Rehabilitation Medicine}

The annual prize of the European Academy of Rehabilitation Medicine, up to CHF. 10,000 - (Swiss francs) will be awarded to an original work about rehabilitation, or to a project of research concerning a present study.

The typewritten text or protocol, in French or English (including a summary in both languages) are to be sent to the secretary office before the 31st of December 2001. Professeur Alex CHANTRAINE, 3, rue Emile Yung, 1205 Genève (Suisse).

\section{Winter Meeting of the European Association of} Neurosurgical Societies (EANS)

7-10 February 2002, Rome, Italy. Further information: Prof Concezio Di Rocco, Institute of Neurosurgery, Catholic University Medical School, Largo, "A. Gemelli" 8,00168 Rome, Italy. e-mail: dirocco@iol.it. Organizing Secretariat: manuela.morandini@ptsroma.it

\section{Scientific Meeting of the American Spinal Injury Association (ASIA)}

3-7 May 2002, Vancouver British Columbia, Canada (in conjunction with IMSOP). For further details please contact: Lesley M Hudson MA, Clinical Meeting Coordinator, American Spinal Injury Association, 2020 Peachtree Road, NW Atlanta, GA30309, USA. Tel: + 1404355 9772; Fax: + 1404355 1826; Website: www.asia-spinalinjury.org 